\title{
FEDERALISMO COOPERATIVO: REFLEXOS NA SAÚDE PÚBLICA
}

\author{
Celia dos Santos Silva, Marcio França Teixeira, Cleberson Aparecido de Morais Silva \\ Universidade do Oeste Paulista - UNOESTE, Presidente Prudente, SP. E-mail: celiasilva@unoeste.br
}

\section{RESUMO}

O presente trabalho trata do Federalismo Cooperativo e seus reflexos na saúde pública. O federalismo é uma forma de Estado que se caracteriza pela união de estados autônomos. O Estado Federal é, portanto, uma aliança ou união de Estados. A formação do Estado Federal brasileiro é caracterizada pelo movimento centrífugo, ou seja, parte do uno para as partes que são classificadas como entidades federativas: União, Estados, Distrito Federal e Municípios. O presente artigo teve como objetivo explanar sobre as questões que dizem respeito ao federalismo e às competências concorrentes previstas na Constituição Federal. Como método, foi desenvolvida sob a ótica da abordagem qualitativa de caráter bibliográfico com embasamento em publicações existentes e a utilização de legislação brasileira. Como resultado e conclusão, observou-se que no inicio do ano de 2020 e 2021 trouxe mais do qualquer cidadão poderia imaginar na mais expansiva e otimista para um novo ano. $O$ governo federal em outros momentos teve e ainda tem um papel centralizador. Governadores agiam, outros não tanto. Em resumo, houve e há uma grande crise no federalismo, tendo como origem a necessidade urgente de medidas a serem tomadas objetivando a proteção da saúde dos administrados. E isso foi feito. Várias medidas foram tomadas, mas muitas vezes alcançando competências de terceiros ou limitando tais competências. Espera-se que esse artigo possa gerar pautas para novas discussões e reflexões para novos estudos.

Palavras- chave: Federalismo. Saúde Pública. Entes Federativos.

\section{COOPERATIVE FEDERALISM: REFLECTIONS IN PUBLIC HEALTH}

\begin{abstract}
This paper deals with Cooperative Federalism and its reflexes on public health. Federalism is a form of state that is characterized by the union of autonomous states. The Federal State is, therefore, an alliance or union of States. The formation of the Brazilian Federal State is characterized by the centrifugal movement, that is, part of the one for the parts that are classified as federative entities: Union, States, Federal District and Municipalities. The purpose of this article was to explain the issues related to federalism and competing competences provided for in the Federal Constitution. As a method, it was developed from the perspective of a qualitative approach of bibliographic character based on existing publications and the use of Brazilian legislation. As a result and conclusion, it was observed that in the beginning of the year 2020 and 2021 it brought more than any citizen could imagine in the most expansive and optimistic for a new year. The federal government at other times had and still has a centralizing role. Governors acted, others less so. In short, there was and is a major crisis in federalism, originating from the urgent need for measures to be taken with a view to protecting the health of the administrated. And that was done. Several measures have been taken, but often reaching third party competencies or limiting those competencies. It is hoped that this article may generate guidelines for new discussions and reflections for new studies.
\end{abstract}

Keywords: Federalism. Public health. Federative loved. 


\section{INTRODUÇÃO}

O início do ano de 2020 ficará eternamente marcado na história mundial. 0 vírus que se propagou em todos os continentes e não fez distinção entre países ricos ou pobres, desenvolvidos ou não desenvolvidos, igualmente alcançou a todos, trazendo as mais diversas e nefastas consequências.

Inicialmente um temor sobre o desconhecido vírus e seu alcance e letalidade situação que ainda vivenciamos -, paralisação de atividades, suspensão de aulas, obrigatoriedade do uso de máscaras, proibição de aglomerações. Muitas das restrições impostas à sociedade são destinadas a sua própria proteção, garantir a vida dos administrados é uma preocupação constante dos Governos, afinal para o alcance do bem comum é necessário garantir a vida em primeiro lugar.

Em função destas restrições foram efetivadas determinações da União, dos Estados Membros, do Distrito Federal e dos municípios, pois referidos Entes buscam o bem comum e tem o dever de agir em consonância com a proteção à vida. É nesse momento de turbilhão de preocupações, tanto dos governos quanto dos administrados, que observamos o conflito entre determinações dos Entes da Federação. Houve uma compatibilização entre as ordens dos governantes? Existiu um trabalho cooperativo?! Qual ordem deve ser observada pelo cidadão?!

Para agir contra o vírus - COVID 1 -19 devem os governos estaduais e municipais esperar orientações da Agência Nacional de Vigilância Sanitária?! O presente artigo se justifica pela incidência endêmica mundial do vírus e tem como objetivo explanar sobre as questões que dizem respeito ao federalismo e às competências concorrentes previstas na Constituição Federal. A seguir segue os métodos adotados para essa pesquisa.

\section{MÉTODOS}

A presente pesquisa foi desenvolvida sob a ótica da abordagem qualitativa de caráter bibliográfico com embasamento em publicações existentes e a utilização de legislação brasileira.

\section{SISTEMA FEDERATIVO}

O federalismo é uma forma de Estado que se caracteriza pela união de estados

\footnotetext{
${ }^{1}$ Corona Vírus Disease - Doença do Coronavírus
}

autônomos, segundo Dallari (2016, p. 251), "Etimologicamente, federação (do latim foedus) quer dizer pacto, aliança. O Estado Federal é, portanto, uma aliança ou união de Estados". Dessa união ocorre o surgimento do Estado Federal, sendo este detentor da soberania, esse movimento centrípeto é característico da formação dos Estados Unidos da América. A formação do Estado Federal brasileiro é caracterizada pelo movimento centrífugo, ou seja, parte do uno para as partes que são classificadas como entidades federativas: União, Estados, Distrito Federal e Municípios.

Adotado na Constituição da República Federativa do Brasil de 1988 (BRASIL, 1988, s. p.), em seu Título III - Da Organização do Estado, o princípio da autonomia dos entes federativos é exposto no artigo 18, caput, "A organização político-administrativa da República Federativa do Brasil compreende a União, os Estados, o Distrito Federal $e$ os Municípios, todos autônomos, nos termos desta Constituição.", ou seja, os entes possuem a responsabilidade de determinar normas político-administrativas, dentro do território de sua competência, sem a interferência de outros entes, desde que respeitem os princípios da Constituição Federal.

Destacam-se dois pontos primordiais ao federalismo na constituição, o primeiro a união indissolúvel dos entes federativos, presente em seu artigo primeiro, ou seja, a segregação de qualquer dos entes do todo não é permitida. $O$ segundo consiste na impossibilidade de abolição da forma federativa de Estado, no artigo 60, § 4으, I (BRASIL, 1988, s.p.), por meio de emenda constitucional. Essas premissas estabelecem uma base sólida para desenvolvimento da organização administrativa estatal, o que é fundamental para o Estado de Direito brasileiro.

A União é uma pessoa jurídica de direito público interno, regida pela autonomia em relação aos estados-membros e municípios. Compete à união resguardar a soberania nacional e representar o Brasil no exterior. Há a separação de poderes denominados de executivo federal, legislativo federal - Congresso Nacional, bicameral, senado e câmara dos deputados - e justiça federal.

Os estados-membros possuem autonomia dividida em três partes: autoorganização e normatização própria, autogoverno e autoadministração, conforme explana Alexandre de Moraes (2019, p. 314). 
Cada estado possui constituição própria, que segue os princípios da Constituição da República, se auto-organizando e legislando acerca das competências que lhe cabem.

Assim como na união, os estados possuem a separação de poderes em executivo, legislativo e judiciário, sendo os dois primeiros escolhidos pelo povo ao qual estão vinculados por meio de eleições periódicas. Vale lembrar que o autogoverno é característica fundamental para autonomia do ente federativo, possibilitando aos governantes um maior poder de decisão para administrar o estado-membro. Por fim, a autoadministração possibilita aos estados-membros o exercício de suas competências administrativas, legislativas e tributárias, cabendo o mantimento de orçamento financeiro suficiente para a manutenção do ente.

Os municípios gozam das mesmas características dos estados-membros, apenas substituindo a constituição estadual pela lei orgânica que possui efeitos similares.

\section{COMPETÊNCIAS}

Nota-se no exposto anterior que há competências comuns aos entes federativos legislativa, administrativa e tributária - sendo necessário efetuar uma repartição, para que haja proporcionalidade na prática administrativa. Para que isso seja feito é preciso fazer uma análise sob a ótica do princípio da predominância do interesse. À união compete o interesse geral, aos estados-membros o interesse regional e aos municípios o interesse local.

O artigo 23 da Constituição Federal $\mathrm{CF}^{2} / 88$ (BRASIL, 1988, s.p.) normatiza as competências comuns aos entes federativos. Tal artigo corresponde ao aspecto solidário, sendo esse a autocomposição na tratativa de matérias comuns. Destaca-se o conceito de cooperação, proporcionando ferramentas legais para tal. Em especial seu inciso II, determina que o direito social à saúde seja dever inerente aos entes.

Essa determinação está exposta também na Lei Federal no 8.080/90 (BRASIL, 1990, s.p.), constitui o Sistema Único de Saúde, em seu artigo 4o diz:

$$
\begin{aligned}
& \text { Art. 4o O conjunto de } \\
& \text { ações e serviços de } \\
& \text { saúde, prestados por } \\
& \text { órgãos e instituições } \\
& \text { públicas federais, }
\end{aligned}
$$

estaduais e municipais, da Administração direta e indireta e das fundações mantidas pelo Poder Público, constitui o Sistema Único de Saúde $\left(S_{U S}^{3}\right)$.

A responsabilidade com a saúde é obrigação de todas as instituições públicas, inclusive os de administração indireta, que devem fazê-la em conjunto.

\section{SERVIÇOS ESSENCIAIS EM TEMPOS DE COVID- 19}

Uma vez que a saúde é de responsabilidade dos entes federativos, cabe a eles, também, garantir em tempos extraordinários os serviços essenciais à população. Os serviços essenciais são atividades que, diante de algumas circunstâncias, seja greve, pandemia ou outras, precisam ser mantidas para que se possam garantir o mínimo necessário à sobrevivência, saúde, abastecimento e segurança da população.

Mas antes é preciso saber a diferença entre serviços essências e serviços públicos essenciais, pois alguns são de competência apenas do Estado. Nesse sentido, Calabrich $(2005$, s.p.) explana que:

Quanto aos serviços essenciais, pode-se dizer que estes são aqueles de vital importância para a sociedade, pois afetam diretamente a saúde, a liberdade ou a vida da população, tendo em vista a natureza dos interesses a cuja satisfação a prestação se endereça. Há aqueles serviços que pela sua própria natureza são ditos essenciais, que são os serviços de segurança nacional, segurança pública e os judiciários. Somente o Estado poderá prestá-los diretamente. São portanto, indelegáveis. (CALABRICH, 2005, s.p.). 
Em virtude da pandemia causada pela chegada do COVID-19, para que os serviços essenciais fossem assegurados para a população brasileira, o presidente da República 'Jair Messias Bolsonaro', por meio do Decreto no 10.282 de 20 de março de 2020, posteriormente alterado pelo decreto no 10.329, de 28 de abril de 2020, regulamentou a Lei no 13.979, de 6 de fevereiro de 2020 que dispõe sobre as medidas para enfrentamento da emergência de saúde pública decorrente do coronavírus (BRASIL, 2020a).

Com isso, junto às medidas para o enfrentamento da emergência de saúde pública do COVID-19, isolamento e quarentena, foram determinadas mais de 50 atividades como sendo indispensáveis ao atendimento das necessidades da comunidade (BRASIL, 2020a). Não obstante, em 2018, durante a paralisação dos caminhoneiros, o Ministério da Saúde em apoio ao governo federal, atuou para garantir a manutenção e continuidade dos atendimentos de urgência e emergência, hospitais, transporte sanitário, rede de hemoderivados e insumos, rede assistencial, entre outros. Essa iniciativa priorizou os atendimentos críticos para manutenção da vida em serviços de saúde (BRASIL, 2018).

Tais medidas são tão necessárias que João Sardi Júnior ao assevera que:

$$
\begin{aligned}
& \text { Tais serviços são na } \\
& \text { verdade indispensáveis a } \\
& \text { vida moderna, e } \\
& \text { basicamente são os pilares } \\
& \text { de uma nação, tanto é que } \\
& \text { quando alguns países se } \\
& \text { declaram guerra os } \\
& \text { primeiros ataques são } \\
& \text { contra alvos ligados aos } \\
& \text { serviços essenciais, pelo } \\
& \text { simples motivo de serem a } \\
& \text { espinha dorsal da infra- } \\
& \text { estrutura do país. (SARDI } \\
& \text { JUNIOR apud FILGUEIRA, } \\
& \text { 2013, s.p.). }
\end{aligned}
$$

Importante salientar que por decisão do Supremo Tribunal Federal - $\mathrm{STF}^{4}$ pela ação direta de Constitucionalidade no 6341, os Estados e Municípios tem competência para adotar medidas de enfrentamento ao coronavírus como ditar regras restritivas quanto ao funcionamento dos serviços essenciais, tais como a diminuição de circulação de funcionários, restrições de horários e número de clientes, distanciamento físico e regras de higiene, no entanto, é preciso considerar o parágrafo 90, incisos I e II do art. 3으 do Decreto no 10.282 de 20 de março de 2020, ou seja, os Estados e Municípios não poderão adotar medidas sobre tudo, mas sim, é preciso considerar a participação da União nos serviços em que a mesma possui interferência (BRASIL, 2020a).

A Constituição Federal de 1988 garante aos entes federativos 0 direito à autoorganização, autogoverno, autoadministração e autonomia tributária e financeira. Mas essa autonomia quando não bem interpretada pode gerar choque entre os entes federados.

\section{CHOQUE ENTRES OS ENTES FEDERATIVOS}

"Cuidar da saúde" é uma das competências comum da União, dos Estados, do Distrito Federal e dos Municípios, mas compete à União, aos Estados e ao Distrito Federal legislar concorrentemente sobre a "proteção e defesa da saúde" (BRASIL, 1988, s.p.), no entanto, em virtude do momento pandêmico com a COVID 19 percebeu-se que, apesar do Brasil possuir um modelo de descentralização territorial e ser formado por uma federação simétrica, houve um crescente movimento de centralização de poder no setor federal propiciando um notório cenário de desequilíbrio federativo no qual o governo federal tentou exclusividade na gestão ao combate à Covid-19.

Com isso os Estados e Municípios dependem exclusivamente do orçamento da União ou leis ditadas pelo Congresso Nacional para que possam fazer algo pelo país. Dessa forma, indiretamente, se tem a visão de que fica difícil definir políticas públicas em favor de seu Estado ou Município. No entanto nos valendo da Constituição Federal de 1988 (BRASIL, 1988, s.p.), é assegurado aos entes federativos competências em relação às questões de saúde e, por assim ser, na visão de Frazão e Mazzuoli (2020), as dificuldades podem ser transformadas em oportunidades de aprendizagem e isso requer o aperfeiçoamento da ideia de competências compartilhadas entre os entes que constituem a divisão político-administrativa do Estado.

Assim, diante de questões federativas que concernem à organização políticoadministrativa eficiente, é necessário que se repensem sobre os aspectos de descentralização e de solidariedade política à medida que crescem as dificuldades com a pandemia, pois, "a

\footnotetext{
${ }^{4}$ Supremo Tribunal Federa
} 
autonomia relativa à "descentralização territorial" não pode justificar qualquer abuso de poder por parte de prefeitos e governadores", tampouco os "[...] governantes não podem abusar do poder que lhes é conferido," esses governos "[...] não podem subestimar a importância dos entes territoriais menores, os quais, muitas vezes, conseguem perceber a chegada de uma crise ou o seu agravamento antes de órgãos de abrangência nacional" (FRAZÃO; MAZZUOLI, 2020, s.p.).

\section{PAPEL DO SUPREMO TRIBUNAL FEDERAL}

Neste período de pandemia diversas demandas alcançaram a alta Corte Jurisdicional Brasileira, não poderíamos aqui fazer menção a muitas delas, mas em especial focaremos na Arguição de Descumprimento de Preceito Fundamental - ADPF ${ }^{5}$ 672-DF, tendo como Requerente o Conselho Federal da Ordem dos Advogados do Brasil $\left(\mathrm{CFOAB}^{7}\right)$ e como relator S.Ex ${ }^{a^{8}}$. o Ministro Alexandre de Morais e, também, na Ação Direta de Inconstitucionalidade no 6.341-DF, tendo como Requerente o Partido Democrático Trabalhista, e como relator, S.Exa . o Ministro Marco Aurélio.

Nesta primeira ação temos o

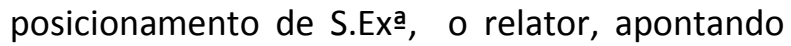
as grandes deficiências e dificuldades entre os posicionamentos entre as autoridades pertencentes a níveis federativos diversos e quanto ao próprio ente federativo, explicitando uma falta de alinhamento dos entes federativos e também de suas próprias estruturas, ou seja, internamente (BRASIL, 2020b).

A ADPF 672 trata também da efetiva aplicação dos princípios e regras de separação dos Poderes e sobre o federalismo, afastando comportamento que possa por em risco a saúde de toda a sociedade, afastando assim desnecessários conflitos federativos, que somente iriam agravar a crise decorrente da pandemia.

Em sequência, decidiu o Supremo Tribunal Federal reconheceu e assegurou o exercício da competência concorrente dos Governos Estaduais e Distrital e suplementar dos Governos Municipais, buscando a adoção de medidas restritivas legalmente permitidas durante a pandemia e indicadas pela própria

\footnotetext{
${ }^{5}$ Arguição de Descumprimento de Preceito Fundamental

${ }^{6}$ Distrito Federal

${ }^{7}$ Conselho Federal da Ordem dos Advogados do Brasil

${ }^{8}$ Sua Excelência
}

Organização Mundial da Saúde ${ }^{9}$ (OMS). Como forma de medidas restritivas podemos indicar a imposição de isolamento, distanciamento social, quarentena, suspensão de atividades de ensino, restrições de comércio, circulação de pessoas, dentre outras.

$\mathrm{Na}$ segunda Ação, $A \mathrm{II}^{10} \mathrm{n}$ ㅇ. 6.341-DF, tendo como relator S.Exa o Ministro Marco Aurélio, buscando ver afastada a competência atribuída pela $M^{11}$ 926/20 à Agência Nacional de Vigilância Sanitária, que deveria indicar recomendação técnica, fundamentada, às autoridades dos demais entes da federação, buscou ser declarada a prévia indicação da Agência em questão(BRASIL, 2020c).

Tal competência atribuída à Agência Nacional de Vigilância Sanitária ofuscava a liberdade dos governantes e a própria cooperação do sistema federativo, sendo esse o entendimento de S.Exa , o relator, Ministro Marco Aurélio, referendada pelo Pleno do Supremo Tribunal Federal em 14.04.20.

Em mais uma decisão, portanto, o Supremo Tribunal Federal afastou qualquer possiblidade de ofensa ao Federalismo, enaltecendo as competências de Estados e Municípios, em especial no combate ao COVID19, bem com suas respectivas autonomias quando de frente da competência concorrente.

\section{CONSIDERAÇÕES FINAIS.}

O inicio do ano de 2020 e 2021 trouxe mais do qualquer cidadão poderia imaginar na mais expansiva e otimista para um novo ano. As novidades como se sabe, não foram e não são das melhores. Inúmeras pessoas infectadas pelo vírus, muitas mortes e um clima de insegurança generalizado, além de incertezas profundas envolvendo a manutenção do Estado, face ao declínio da arrecadação.

Essas já seriam situações suficientes para que as expectativas ficassem frustradas, fossem transformadas em decepções, em falta de esperança e a certeza de um olhar incerto para o porvir. Mas não tivemos somente essas situações como negativas. Tivemos mais. Diante da nova realidade verificamos que houve um atropelo nas competências atribuídas a cada ente da federação.

Governadores e Prefeitos em alguns momentos ficaram dependentes. O governo

\footnotetext{
${ }^{9}$ Organização Mundial da Saúde

${ }^{10}$ Ação Direta de Inconstitucionalidade

${ }^{11}$ Medida Provisória
} 
federal em outros momentos teve um papel centralizador. Governadores agiam, outros não tanto.

Em resumo, houve e há uma grande crise no federalismo, tendo como origem a necessidade urgente de medidas a serem tomadas objetivando a proteção da saúde dos administrados. E isso foi feito. Várias medidas foram tomadas, mas muitas vezes alcançando competências de terceiros ou limitando tais competências. Esse conflito de competências, como visto, acabou chegando até o Supremo Tribunal Federal, que, como guardião da Constituição Federal, bem decidiu defendendo o Federalismo e, por consequência, a Constituição Federal. Será?

Espera-se que esse artigo possa gerar pautas para novas discussões e reflexões para novos estudos.

\section{REFERÊNCIAS}

BRASIL. Constituição (1988). Constituição da República Federativa do Brasil. Brasília, DF: Senado Federal, 1988.

BRASIL. Presidência da República. Lei no 8.080, de 19 de setembro de 1990. Lei Orgânica da Saúde. Dispõe sobre as condições para a promoção, proteção e recuperação da saúde, a organização e o funcionamento dos serviços correspondentes e dá outras providências. Brasília, 1990. Disponível em: http://www.planalto.gov.br/ccivil 03/leis/18080. htm. Acesso em: 10 ago. 2020.

BRASIL. Ministério da Saúde. Governo Federal atua para garantir serviços essenciais à saúde. Brasília, 2018. Disponível em: https://www.saude.gov.br/noticias/agenciasaude/43362-governo-federal-atua-para-garantirservicos-essenciais-a-saude. Acesso em: 06 ago. 2020.

BRASIL. Presidência da República. Subchefia para Assuntos Jurídicos. DECRETO № 10.282, de 20 de março de 2020. Regulamenta a Lei no 13.979, de 6 de fevereiro de 2020, para definir os serviços públicos e as atividades essenciais. Brasília, 2020. Disponível em: http://www.planalto.gov.br/ccivil_03/_ato20192022/2020/decreto/D10282.htm. Acesso em: 03 ago. 2020a.
BRASIL. Supremo Tribunal Federal. Arguição de Descumprimento de Preceito Fundamental no 672-DF. Relator: Ministro Alexandre de Morais. Pesquisa de Jurisprudência. Disponível em: http://www.stf.jus.br/arquivo/cms/noticiaNoticia Stf/anexo/ADPF672liminar.pdf. Acesso em: 19 ago. 2020b.

BRASIL. Supremo Tribunal Federal. Medida cautelar na ação direta de inconstitucionalidade 6.341 distrito federal. Relator: Ministro Marco Aurélio. Pesquisa de Jurisprudência. Brasília, mar. $2020 . \quad$ Disponível em: http://www.stf.jus.br/arquivo/cms/noticiaNoticia Stf/anexo/ADI6341.pdf. Acesso em: 19. ago. 2020c.

CALABRICH, Ingo Sá Hage. Ações sobre a greve em atividades essências. Migalhas, ago., 2005. Disponível em:

https://www.migalhas.com.br/depeso/15015/ac oes-sobre-a-greve-em-atividades-essencias. Acesso em: 08 ago. 2020.

DALLARI, Dalmo de Abreu. Elementos da Teoria Geral do Estado. 33. ed. São Paulo: Saraiva, 2016.

FILGUEIRA, Rayane de Almeida. A Interrupção de Serviços Públicos Essenciais pelo inadimplemento do usuário. Juris Way Sistema Educacional Online, set., 2013. Disponível em: https://www.jurisway.org.br/v2/dhall.asp?id_dh= 11698. Acesso em: 08 ago. 2020.

FRAZÃO, Hugo Abas; MAZZUOLI, Valério de Oliveira. O que a pandemia pode ensinar para Itália e Brasil sobre federalismo? Consultor Jurídico, maio, 2020. Disponível em: https://www.conjur.com.br/2020-mai-12/frazaomazzuoli-federalismo-durante-covid-19. Acesso em: 10 ago. 2020.

MORAES, Alexandre de. Direito constitucional. 35. ed. São Paulo: Atlas, 2019. 